\title{
Robust Output Tracking of Uncertain Large-Scale Input-Delay Systems via Decentralized Fuzzy Sliding Mode Control
}

\author{
Chiang-Che ng Chiang
}

Department of Electrical Engin eering, Tatung Univ ersity, 40 Chung-Shan North Road, Sec.3, Taip ei, Taiwan, Republic of China

\begin{abstract}
This paper deals with the robust output tracking problem of uncertain large-scale systems with input delay and the time-delay interconnections. Due to the information transmission between subsystems, time delays are often encountered in large-scale systems and lead to the source of system instability. First, the original nonlinear time-delay systems can be represented by the Takagi-Sugeno fuzzy model, which combines some simple local linear time-delay systems with their linguistic description. Then, a feasible and systematic design scheme is presented to synthesize the decentralized fuzzy-model-based sliding mode controller. The adaptive fuzzy approach is proposed to approximate the upper bound of the uncertainties including the time-delay interconnections and the input delay. Based on the Lyapunov stability theorem, the proposed control scheme can not only guarantee the robust stability of the whole closed-loop system with input delay and time-delay interconnections, but also obtain the good tracking performance. Finally, simu lation results are given to confirm the effectiveness of the proposed controller in this paper.
\end{abstract}

Keywords Decentralized Control, Large-Scale Systems, Output Tracking, Input Delay, Fuzzy Model, Sliding Mode Control

\section{Introduction}

Recently, there have been a number of research works on stability analysis and design for a class of large-scale interconnected systems, such as electrical networks, nuclear reactors, and hydraulic systems, etc. Due to the large-scale system with interconnected terms, the decentralized controller is preferred to be adopted as a control methodology such that design procedures can be simplified and the computational burden can be shared by all the subsystem controllers[1-5]. In fact, for the complexity of large-scale systems, the uncertainty and time delay are often encountered in these systems. Therefore, the problem of control design and stabilization for a class of large-scale systems with uncertainties and time delays becomes an important topic.

In practices, due to the in formation transmission between subsystems, time delays inevitably occur in large-scale systems. Also, the existence of time delays is often a source of instability in various engineering systems. Therefore, the stabilization problem of large-scale systems with delayed states and the time-delay interconnections has been widely

* Corresponding author:

ccchiang@ttu.edu.tw (Chiang-Cheng Chiang)

Published online at http:/journal.sapub.org/control

Copyright (C) 2012 Scientific \& Academic Publishing. All Rights Reserved studied in the literature[6-10]. It has been shown that the presence of input delays, if not considered in a controller design, may cause instability or serious deterioration in the performance of the resulting nonlinear control systems [11-14]. In this study, the problem of the decentralized control for a class of input-delayed large-scale systems with the time-delay interconnections is investigated.

On the other hand, fuzzy logic control has been successfully applied to the control design of nonlinear control systems[15-18]. It is well-known that fuzzy logic control, which is based on fuzzy sets and fuzzy reasoning with a set of linguistic control rules, does not need a rigorous mathematical model and is more insensitive to plant parameter variations and noise disturbance. It has been shown that the method of T-S fuzzy models, in terms of IF-THEN rules with a linear input-output relation, gives an effective and feasible approach to the control problem of complex nonlinear systems[19-23]. Therefore, in this study, the proposed control scheme is based on the T-S fuzzy model to deal with the control design of uncertain large-scale system with delayed input and time-delay interconnections.

Sliding-mode control (SMC) systems have been extensively studied and widely applied to many engineering systems. Due to its good robustness to uncertainties, sliding mode control has proven to be an effective method for robust control of nonlinear systems. In recent literature, some researchers proposed the design methods of fuzzy logic 
control based on sliding-mode approaches for a class of ill-defined or poorly modelled systems [24-29]. Recently, the stability and control design of large-scale systems has attracted the attention of many control researchers and been studied extensively[30-34]. Wang et al.[33] and Hsiao et al.[34] presented linear state feedback control approaches based on T-S fuzzy model for the large-scale system, respectively. Un like previous works, this paper is to present a different control scheme to tackle the problem of large-scale systems with delayed input and the time-delay interconnections, without the assumption that the upper bounds of the interconnections and modelling errors must be known.

This paper is concerned with the robust stability and output tracking control problem of decentralized fuzzy-model-based sliding mode controller for uncertain large-scale systems with delayed input and the time-delay interconnections. First, in this paper the original nonlinear time-delay large-scale systems can be represented by the Takagi-Sugeno fuzzy model, which combines some simple local linear time-delay systems with their linguistic description. Then, an effective and feasible design scheme is developed to synthesize the proposed decentralized fuzzy-model-based sliding mode controller with some adaptive fuzzy laws to approximate the upper bound of the uncertainties including the time-delay interconnections and the delayed input. Finally, simulation results are given to demonstrate the validity of the proposed controller in this paper.

The rest of this paper are organized as follows. In Section 2 , some properties of the T-S fuzzy system are reviewed, and the large-scale systems with time delays and uncertainties are formulated in detail. Furthermore, the control design method to synthesize the proposed decentralized fuzzymodel-based sliding mode controller and the analysis of robust stability are included in Section 3. In Section 4, simu lation results are given to verify the effectiveness of the proposed decentralized controller in this paper. At last, a conclusion is given in Section 5.

\section{Problem Formulation}

The fuzzy dynamic model, proposed by Takagi and Sugeno, is described by fuzzy IF-THEN rules, which represents local linear input-output relations of nonlinear systems. Let us consider the uncertain input-delayed large-scale systems with time-delay interconnections which can be described by the following fu zzy model:

$$
\begin{aligned}
& R_{i}^{l}: \text { if } \theta_{i 1} \text { is } F_{i 1}^{l} \text {, and } \theta_{i 2} \text { is } F_{i 2}^{l} \text {, and } \cdots \text { and, } \theta_{i_{n i}} \text { is } F_{i_{n i}}^{l} \\
& \text { then } \dot{x}_{i}(t)=A_{i}^{l} x_{i}(t)+B_{i}^{l} u_{i}(t-\tau)+\sum_{\substack{j=1 \\
j \neq i}}^{N} A_{i j}^{l} x_{j}\left(t-\tau_{i j}(t)\right)+f_{i}^{l}\left(x_{i}(t), t\right),
\end{aligned}
$$

where $x_{i}(t)=\left[x_{i 1}(t), \cdots, x_{i n_{i}}(t)\right]^{T}$ with $\dot{x}_{i 1}(t)=x_{i 2}(t), \dot{x}_{i 2}(t)=x_{i 3}(t), \cdots, \dot{x}_{i n_{i}-1}(t)=x_{i n_{i}}(t), \quad u_{i}(t-\tau) \in R$ is the manipulated input of $i$ th subsystem, the delays $\tau>0$ and $\tau_{i j}>0$ denote the input-delayed and time delay in the interconnections, respectively. $R_{i}^{l}\left(l=1,2, \cdots, r_{i}\right)$ denotes the $l$ th fuzzy inference rule of $i$ th subsystem, $r_{i}$ is the number of rules, $F_{i q}^{l}\left(q=1,2, \cdots, n_{i}\right)$ are fuzzy set, $\theta_{i 1}-\theta_{i_{n i}}$ are the premise variables. $A_{i}^{l} \in R^{n_{i} \times n_{i}}$ and $B_{i}^{l} \in R^{n_{i} \times 1}$ are constant matrices in controllability canonical form and given by

$$
A_{i}^{l}=\left[\begin{array}{ccccc}
0 & 1 & 0 & \cdots & 0 \\
0 & 0 & 1 & \cdots & 0 \\
\vdots & \vdots & \vdots & \ddots & \vdots \\
0 & 0 & 0 & \cdots & 1 \\
a_{i 1}^{l} & a_{i 2}^{l} & a_{i 3}^{l} & \cdots & a_{i n_{i}}^{l}
\end{array}\right], B_{i}^{l}=\left[\begin{array}{c}
0 \\
0 \\
\vdots \\
0 \\
b_{i n_{i}}^{l}
\end{array}\right],
$$

$A_{i j}^{l} \in R^{n_{i} \times n_{i}}$ and $f_{i}^{l}\left(x_{i}(t), t\right)$ are defined as follows: 


$$
A_{i j}^{l}=\left[\begin{array}{ccccc}
0 & 0 & 0 & \cdots & 0 \\
0 & 0 & 0 & \cdots & 0 \\
\vdots & \vdots & \vdots & \ddots & \vdots \\
0 & 0 & 0 & \cdots & 0 \\
a_{i j 1}^{l} & a_{i j 2}^{l} & a_{i j 3}^{l} & \cdots & a_{i j n_{j}}^{l}
\end{array}\right], f_{i}^{l}\left(x_{i}(t), t\right)=\left[\begin{array}{c}
0 \\
0 \\
0 \\
\vdots \\
\Delta f_{i n_{i}}^{l}
\end{array}\right]
$$

which represent the interconnection matrix and the nonlinear perturbation, respectively, where $a_{i j 1}^{l}, a_{i j 2}^{l}, \cdots, a_{i j n_{i}}^{l}$ and $\Delta f_{i n_{i}}^{l}$ are unknown.

Assumption 1: All pairs $\left(A_{i}^{l}, B_{i}^{l}\right), i=1,2, \cdots, N$, are controllable.

By using the fu zzy inference method with a singleton fu zzifier, product inference, and center-average defu zzifier, the fu zzy model (1) can be expressed as the following global model:

$$
\dot{x}_{i}(t)=\sum_{l=1}^{r_{i}} h_{i}^{l}\left[A_{i}^{l} x_{i}(t)+B_{i}^{l} u_{i}(t-\tau)+\sum_{\substack{j=1 \\ j \neq i}}^{N} A_{i j}^{l} x_{j}\left(t-\tau_{i j}(t)\right)+f_{i}^{l}\left(x_{i}(t), t\right)\right]
$$

where $h_{i}^{l}\left(\theta_{i q}(t)\right)=\frac{w_{i}^{l}\left(\theta_{i q}(t)\right)}{\sum_{l=1}^{r_{i}} w_{i}^{l}\left(\theta_{i q}(t)\right)}, w_{i}^{l}\left(\theta_{i q}(t)\right)=\prod_{i q=1}^{n_{i}} F_{i q}^{l}\left(\theta_{i q}(t)\right)$, and $F_{i q}^{l}\left(\theta_{i q}(t)\right)$ is the grade of membership of $\theta_{i q}(t)$ in $F_{i q}^{l}$. It is seen that $w_{i}^{l}\left(\theta_{i q}(t)\right) \geq 0, \sum_{l=1}^{r_{i}} w_{i}^{l}\left(\theta_{i q}(t)\right) \geq 0, \quad l=1,2, \cdots, r_{i}$, for all $t$. Therefore, $h_{i}^{l}\left(\theta_{i q}(t)\right) \geq 0, \sum_{l=1}^{r_{i}} h_{i}^{l}\left(\theta_{i q}(t)\right)=1$, for all $t$.

Accordingly, the main controlobjective of this paper is to utilize the decentralized fuzzy-model-based sliding mode control $u_{i}(t)$ such that the robust stability of the whole closed-loop system with input delay and time-delay interconnections can be guaranteed.

\section{Decentralized Fuzzy-Model-Based Adaptive Sliding Mode Controller Design}

In this section, the control objective is to design a decentralized fuzzy-model-based sliding mode control scheme such that the desired state trajectory of the closed-loop system is ach ieved and the effects of systemuncertainty can be attenuated while maintaining the boundedness of all signals inside the control loops.

Using the T-S fuzzy model (4) of the original system, it can be obtained that

$$
\begin{aligned}
& \dot{x}_{i}(t)=\sum_{l=1}^{r_{i}} h_{i}^{l}\left[A_{i}^{l} x_{i}(t)+B_{i}^{l} u_{i}(t)+B_{i}^{l} u_{i}(t-\tau)-B_{i}^{l} u_{i}(t)+\right. \\
& \left.\sum_{\substack{j=1 \\
j \neq i}}^{N} A_{i j}^{l} x_{j}\left(t-\tau_{i j}(t)\right)+f_{i}^{l}\left(x_{i}(t), t\right)\right]
\end{aligned}
$$

From (2), (3), and (5), we obtain

$$
\dot{x}_{i}(t)=\sum_{l=1}^{r_{i}} h_{i}^{l}\left[A_{i}^{l} x_{i}(t)+B_{i}^{l} u_{i}(t)+\sum_{j=1}^{N} \Delta_{i j}^{l}\right]
$$

or equivalently of the form 


$$
\begin{aligned}
\dot{x}_{i n_{i}}(t) & =\sum_{l=1}^{r_{i}} h_{i}^{l}\left[\left(a_{i 1}^{l} x_{i 1}(t)+a_{i 2}^{l} x_{i 2}(t)+\cdots+a_{i n_{i}}^{l} x_{i n_{i}}(t)\right)\right. \\
& \left.+b_{i n_{i}}^{l} u_{i}(t)+\sum_{j=1}^{N} \bar{\Delta}_{i j}^{l}\right] .
\end{aligned}
$$

where

$$
\begin{aligned}
\sum_{j=1}^{N} \Delta_{i j}^{l} & =\sum_{\substack{j=1 \\
j \neq i}}^{N} A_{i j}^{l} x_{j}\left(t-\tau_{i j}^{l}(t)\right)+f_{i}^{l}\left(x_{i}(t), t\right)+B_{i}^{l} u_{i}(t-\tau)-B_{i}^{l} u_{i}(t) \\
& =\sum_{\substack{j=1 \\
j \neq i}}^{N} A_{i j}^{l} x_{j}\left(t-\tau_{i j}(t)\right)+f_{i}^{l}\left(x_{i}(t), t\right)+B_{i}^{l}\left(u_{i}(t-\tau)-u_{i}(t)\right)
\end{aligned}=\left[\begin{array}{c}
0 \\
0 \\
0 \\
\vdots \\
\sum_{j=1}^{N} \bar{\Delta}_{i j}^{l}
\end{array}\right] .
$$

and

$$
\begin{aligned}
& \sum_{j=1}^{N} \bar{\Delta}_{i j}^{l}=\sum_{\substack{j=1 \\
j \neq i}}^{N}\left(a_{i j 1}^{l} x_{j 1}(t)+a_{i j 2}^{l} x_{j 2}(t)+\cdots+a_{i j n_{j}}^{l} x_{j n_{j}}(t)\right) \\
& +\Delta f_{i n_{i}}^{l}+b_{i n_{i}}^{l}\left(u_{i}(t-\tau)-u_{i}(t)\right)
\end{aligned}
$$

Define the controller as the following form:

$$
u_{i}(t)=\frac{1}{\sum_{l=1}^{r_{i}} h_{i}^{l} b_{i n_{i}}^{l}}\left[-\sum_{l=1}^{r_{i}} h_{i}^{l}\left(a_{i 1}^{l} x_{i 1}(t)+a_{i 2}^{l} x_{i 2}(t)+\cdots+a_{i n_{i}}^{l} x_{i n_{i}}(t)\right)+u_{s i}(t)\right]
$$

where $u_{s i}(t)$ will be determined in the latter.

Substituting (10) into (7), it y ields

$$
\left\{\begin{aligned}
& \dot{x}_{i 1}(t)=x_{i 2}(t), \\
& \dot{x}_{i 2}(t)=x_{i 3}(t), \\
& \vdots \\
& \dot{x}_{i n_{i}}(t)=u_{s i}(t)+\sum_{l=1}^{r_{i}} \sum_{j=1}^{N} h_{i}^{l} \bar{\Delta}_{i j}^{l} .
\end{aligned}\right.
$$

The control objective is to drive the state $x_{i}(t)$ to track a specific desired $x_{d i}(t)=\left[x_{d i 1}(t), x_{d i 2}(t), \cdots, x_{d i i_{i}}(t)\right]^{T} \quad, \quad$ where $\dot{x}_{d i \alpha-1}=x_{d i \alpha}$ for $\alpha=1,2, \cdots, n_{i}$.

Assumption 2: The desired state $x_{d i}(t)=\left[x_{d i 1}(t), x_{d i 2}(t), \cdots, x_{d i i_{i}}(t)\right]^{T}$ for the $i$ th subsystem is continuous and available, and $\left\|x_{d i}(t)\right\| \leq \Phi_{i}$ with $\Phi_{i}$ being a known positive bounded constant.

Let the tracking error vector of the $i$ th subsystem be defined as 


$$
e_{i}(t)=\left[e_{i 1}(t), e_{i 2}(t), \cdots, e_{i n_{i}}(t)\right]^{T}
$$

where $e_{i \beta}(t)=x_{i \beta}(t)-x_{d i \beta}(t), \quad \beta=1,2, \cdots n_{i}$, and $i=1,2, \cdots, N$.

From(6), (9), and (10), the error dynamic systemof the $i$ th subsystem can be expressed as

$$
\left\{\begin{array}{l}
\dot{e}_{i 1}(t)=e_{i 2}(t) \\
\dot{e}_{i 2}(t)=e_{i 3}(t), \\
\vdots \\
\dot{e}_{i n_{i}-1}(t)=e_{i n_{i}}(t) \\
\dot{e}_{i n_{i}}(t)=u_{s i}(t)+\sum_{l=1}^{r_{i}} \sum_{j=1}^{N} h_{i}^{l} \bar{\Delta}_{i j}^{l}-\dot{x}_{d i n_{i}}(t)
\end{array}\right.
$$

Assumption 3: The results after comb ining input-delayed and time-delay interconnections with perturbation in the system (13) are bounded by

$$
\sum_{l=1}^{r_{i}} \sum_{j=1}^{N} h_{i}^{l} \bar{\Delta}_{i j}^{l} \leq \xi_{i 0}+\sum_{j=1}^{N} \xi_{i j}\left(x_{j}\right),
$$

where $\xi_{i 0}$ are unknown constants and smooth functions $\xi_{i j}\left(x_{j}\right)$ are unknown s mooth functions with $\xi_{i j}(0)=0$.

To solve these situations, we employ an adaptive gain $\hat{\xi}_{i 0}$ to adapt the unknown constant $\xi_{i 0}$ and the fuzzy logic system $\hat{\xi}_{i j}\left(x_{j} \mid \theta_{i j}\right)$ to approximate unknown functions $\xi_{i j}\left(x_{j}\right)$ respectively.

In this case, we replace $\xi_{i j}\left(x_{j}\right)$ by the fuzzy logic system $\hat{\xi}_{i j}\left(x_{j} \mid \theta_{i j}\right)$, where $\hat{\xi}_{i j}\left(x_{j} \mid \theta_{i j}\right)$ is the fuzzy system with singleton fuzzifier, center-average defuzzifier, and product inference are the following form:

$$
\hat{\xi}_{i j}\left(x_{j} \mid \theta_{i j}\right)=\frac{\sum_{l=1}^{r_{i}} \theta_{i j}\left[\prod_{i=1}^{N} \mu_{F_{i}^{l}}\left(x_{j}\right)\right]}{\sum_{l=1}^{r_{i}}\left[\prod_{i=1}^{N} \mu_{F_{i}^{l}}\left(x_{j}\right)\right]} .
$$

Define the fuzzy basis function as

$$
\eta^{l}\left(x_{j}\right)=\frac{\prod_{i=1}^{N} \mu_{F_{i}^{l}}\left(x_{j}\right)}{\sum_{l=1}^{r_{i}}\left(\prod_{i=1}^{N} \mu_{F_{i}^{l}}\left(x_{j}\right)\right)},
$$

where $\mu_{F_{i}^{l}}\left(x_{j}\right)$ are Triangular membership functions. Then the fuzzy logic system (15) is equivalent to a fuzzy basis function expansion

$$
\hat{\xi}_{i j}\left(x_{j} \mid \theta_{i j}\right)=\theta^{T} \eta\left(x_{j}\right),
$$

where $\eta\left(x_{j}\right)=\left[\eta^{1}\left(x_{j}\right), \cdots, \eta^{r_{i}}\left(x_{j}\right)\right]^{T}$ is a regressive vector with the regressor $\eta^{M}\left(x_{j}\right)$ defined as a fuzzy basis function, and $\theta=\left[\theta_{i j}^{1}, \theta_{i j}^{2}, \cdots, \theta_{i j}^{r_{i}}\right]^{T}$ are the corresponding parameter vectors of the fuzzy logic system. Define the optimal parameter vector of fuzzy logic system $\theta_{i j}^{*}$ and the minimum approximation error as

$$
\begin{gathered}
\theta_{i j}^{*}=\arg \min _{\theta_{\mathrm{ij}} \in \Omega_{i j}}\left\{\sup _{x_{j} \in R^{n_{i}}}\left|\xi_{i j}\left(x_{j}\right)-\hat{\xi}_{i j}\left(x_{j} \mid \theta_{i j}\right)\right|\right\}, \\
\omega_{i}=\sum_{J=1}^{N} \xi_{i j}\left(x_{j}\right)-\sum_{j=1}^{N} \hat{\xi}_{i j}\left(x_{j} \mid \theta_{i j}^{*}\right)
\end{gathered}
$$

where $\Omega_{i j}$ is the convex compact set, which contain the feasible parameter set for $\theta_{i j}^{*}$, and $\widetilde{\theta}_{i j}=\theta_{i j}^{*}-\theta_{i j}$, denotes the parameter estimation error.

Then, we adapt minimum approximation error $\omega_{i}$ of utilizing the adaptive gain $\hat{\omega}_{i}$, therefore, we can define adaptation error of minimu m approximation error as

$$
\widetilde{\omega}_{i}=\omega_{i}-\hat{\omega}_{i},
$$

and the adaptation error of adaptive gain $\hat{\zeta}_{i 0}$ is defined as

$$
\widetilde{\xi}_{i 0}=\xi_{i 0}-\hat{\xi}_{i 0} .
$$

According to the proposed decentralized sliding mode control scheme in (10), the composite switching hyperplane is defined by letting the composite switching vector $S=\left[S_{1} S_{2} \cdots S_{N}\right]^{T}=0$, where the sliding surface of each subsystem is selected as the following form:

$$
S_{i}=e_{i n_{i}}+c_{i 1} e_{i\left(n_{i}-1\right)}+\cdots+c_{i\left(n_{i}-2\right)} e_{i 2}+c_{i\left(n_{i}-1\right)} e_{i 1}
$$

where $c_{k}>0$ for $1 \leq k \leq n_{i}-1$, and $c_{k}, k=1,2, \cdots, n_{i}-1$ are chosen such that the following polynomial

$$
L(s)=s^{n_{i}-1}+c_{i 1} s^{n_{i}-2}+\cdots+c_{i(r-2)} s+c_{i(r-1)}
$$

is Hurwitz and $S$ is the Laplace operator. Thus, when the state error trajectories reach the sliding surface $S_{i}=0$ and slide 
along the surface i.e.

$$
e_{1}^{\left(n_{i}-1\right)}+c_{i 1} e_{1}^{\left(n_{i}-2\right)}+\cdots+c_{i(\gamma-2)} \dot{e}_{1}+c_{i(\gamma-1)} e_{1}=0
$$

it implies that tracking error tends to zero as $t \rightarrow \infty$. Based on Assumption 3, we get the decentralized control law as follows:

$$
\begin{aligned}
& u_{s i}(t)=-K_{i} S_{i}-\hat{\zeta}_{i 0}-\sum_{j=1}^{N} \hat{\zeta}_{i j}\left(x_{j} \mid \theta_{i j}\right) \\
& +\dot{x}_{d i n_{i}}-c_{i 1} \dot{e}_{i n_{i}-1} \cdots-c_{i n_{i}-2} \dot{e}_{i 2}-c_{i n_{i}-1} \dot{e}_{i 1}-\hat{\omega}_{i}
\end{aligned}
$$

where $K_{i}>0$. By taking the time derivative of both sides of (22), we can obtain

$$
\begin{aligned}
\dot{S}_{i}= & \dot{e}_{i n_{i}}+c_{i 1} \dot{e}_{i n_{i}-1}+\cdots+c_{i n_{i}-2} \dot{e}_{i 2}+c_{i n_{i}-1} \dot{e}_{i 1} \\
= & u_{s i}(t) \\
& +\sum_{l=1}^{r_{i}} \sum_{j=1}^{N} h_{i}^{l} \bar{\Delta}_{i j}^{l}-\dot{x}_{d i n_{i}}(t)+c_{i 1} \dot{e}_{i n_{i}-1}+\cdots+c_{i n_{i}-2} \dot{e}_{i 2}+c_{i n_{i}-1} \dot{e}_{i 1} .
\end{aligned}
$$

Now, the following adaptive laws for those unknown parameters in (14) and (19) are chosen as:

$$
\begin{gathered}
\dot{\hat{\omega}}_{i}=\gamma_{i 1} S_{i}, \\
\dot{\theta}_{i j}=\gamma_{i 2} S_{i} \eta\left(x_{j}\right), \\
\dot{\hat{\xi}}_{i 0}=\gamma_{i 3} S_{i},
\end{gathered}
$$

where $\gamma_{i 1}, \gamma_{i 2}$, and $\gamma_{i 3}$ are positive constants specified by the designer. The proposed control law will guarantee the asymptotical stability for the error dynamics of (13), and it will be proved in the following theorem.

Theorem 1: For the subsystems consisting of (1), the decentralized fuzzy-model-based sliding mode control law is chosen as (10) with (25), and consider the adaptation laws (27)-(29). If Assumptions 1-3 are satisfied, then the following properties are guaranteed:

1). All the signals in the closed-loop system are bounded.

2). The tracking error $e_{i}(t)$ decreases asymptotically to zero.

Proof: In order to prove this theorem, we consider the following Lyapunov function:

$$
V=\sum_{i=1}^{N} V_{1 i}+\sum_{i=1}^{N} V_{2 i}
$$

where

$$
\begin{gathered}
V_{1 i}=\frac{1}{2} S_{i}^{2}, \\
V_{2 i}=\frac{1}{2}\left[\frac{1}{\gamma_{i 1}} \widetilde{\omega}_{i}^{2}+\frac{1}{\gamma_{i 2}} \sum_{j=1}^{N} \widetilde{\theta}_{i j}^{T} \widetilde{\theta}_{i j}+\frac{1}{\gamma_{i 3}} \widetilde{\xi}_{i 0}^{2}\right] .
\end{gathered}
$$

Using the control of $u_{s i}(t)$, the sliding surface may be expressed as 


$$
\begin{aligned}
\dot{S}_{i}= & u_{s i}(t)+\sum_{l=1}^{r_{i}} \sum_{j=1}^{N} h_{i}^{l} \bar{\Delta}_{i j}^{l}-\dot{x}_{d i n_{i}}(t)+c_{i 1} \dot{e}_{i n_{i}-1}+\cdots+c_{i n_{i}-2} \dot{e}_{i 2}+c_{i n_{i}-1} \dot{e}_{i 1} \\
\leq & u_{s i}(t)+\xi_{i 0}+\sum_{j=1}^{N} \xi_{i j}\left(x_{j}\right)-\dot{x}_{d i n_{i}}+c_{i 1} \dot{e}_{i n_{i}-1}+\cdots+c_{i n_{i}-2} \dot{e}_{i 2}+c_{i n_{i}-1} \dot{e}_{i 1} \\
= & -K_{i} S_{i}-\hat{\zeta}_{i 0}-\sum_{j=1}^{N} \hat{\zeta}_{i j}\left(x_{j} \mid \theta_{i j}\right)+\dot{x}_{d i n_{i}}-c_{1} \dot{e}_{i n_{i}-1}-\cdots-c_{n_{i}-2} \dot{e}_{i 2}-c_{n_{i}-1} \dot{e}_{i 1} \\
& -\hat{\omega}_{i}+\xi_{i 0}+\sum_{j=1}^{N} \xi_{i j}\left(x_{j}\right)-\dot{x}_{d i n_{i}}+c_{i 1} \dot{e}_{i n_{i}-1}+\cdots+c_{i n_{i}-2} \dot{e}_{i 2}+c_{i n_{i}-1} \dot{e}_{i 1} \\
= & -K_{i} S_{i}+\tilde{\xi}_{i 0}+\left(\sum_{j=1}^{N} \xi_{i j}\left(x_{j}\right)-\sum_{j=1}^{N} \hat{\xi}_{i j}\left(x_{j} \mid \theta_{i j}^{*}\right)+\sum_{j=1}^{N} \hat{\xi}_{i j}\left(x_{j} \mid \theta_{i j}^{*}\right)-\sum_{j=1}^{N} \hat{\xi}_{i j}\left(x_{j} \mid \theta_{i j}\right)\right)-\hat{\omega}_{i} \\
=- & K_{i} S_{i}+\tilde{\xi}_{i 0}+\tilde{\omega}_{i}+\sum_{j=1}^{N} \tilde{\theta}_{i j}^{T} \eta\left(x_{j}\right)
\end{aligned}
$$

Then the derivative of $V_{1 i}$ can be stated as follows:

$$
\dot{V}_{1 i}=S_{i} \dot{S}_{i} \leq S_{i}\left(-K_{i} S_{i}+\tilde{\xi}_{i 0}+\tilde{\omega}_{i}+\sum_{j=1}^{N} \tilde{\theta}_{i j}^{T} \eta\left(x_{j}\right)\right)
$$

Thus, we get

$$
\sum_{i=1}^{N} \dot{V}_{1 i} \leq \sum_{i=1}^{N} S_{i}\left(-K_{i} S_{i}+\widetilde{\xi}_{i 0}+\widetilde{\omega}_{i}+\sum_{j=1}^{N} \widetilde{\theta}_{i j}^{T} \eta\left(x_{j}\right)\right) .
$$

Then, computing the time derivative of $V_{2 i}$, we have

$$
\dot{V}_{2 i}=\frac{1}{\gamma_{i 1}} \widetilde{\omega}_{i} \dot{\tilde{\omega}}_{i}+\frac{1}{\gamma_{i 2}} \sum_{j=1}^{N} \widetilde{\theta}_{i j}^{T} \dot{\widetilde{\theta}}_{i j}+\frac{1}{\gamma_{i 3}} \widetilde{\xi}_{i 0} \dot{\tilde{\xi}}_{i 0} .
$$

By the fact $\dot{\widetilde{\sigma}}_{i}=-\dot{\hat{\omega}}_{i}, \dot{\widetilde{\theta}}_{i j}=-\dot{\theta}_{i j}$, and $\dot{\widetilde{\xi}}_{i 0}=-\dot{\hat{\xi}}_{i 0}$, the above equation becomes

$$
\dot{V}_{2 i}=-\frac{1}{\gamma_{i 1}} \widetilde{\omega}_{i} \dot{\hat{\omega}}_{i}-\frac{1}{\gamma_{i 2}} \sum_{j=1}^{N} \widetilde{\theta}_{i j}^{T} \dot{\theta}_{i j}-\frac{1}{\gamma_{i 3}} \widetilde{\xi}_{i 0} \dot{\hat{\xi}}_{i 0},
$$

so

$$
\sum_{i=1}^{N} \dot{V}_{2 i}=\sum_{i=1}^{N}\left[-\frac{1}{\gamma_{i 1}} \widetilde{\omega}_{i} \dot{\hat{\omega}}_{i}-\frac{1}{\gamma_{i 2}} \sum_{J=1}^{N} \widetilde{\theta}_{i j}^{T} \dot{\theta}_{i j}-\frac{1}{\gamma_{i 3}} \widetilde{\xi}_{i 0} \dot{\hat{\xi}}_{i 0}\right]
$$

Thus from (27)-(29), we obtain 


$$
\begin{aligned}
\dot{V} & =\sum_{i=1}^{N} \dot{V}_{1 i}+\sum_{i=1}^{N} \dot{V}_{2 i} \\
& \leq \sum_{i=1}^{N} S_{i}\left(-K_{i} S_{i}+\tilde{\xi}_{i 0}+\tilde{\omega}_{i}+\sum_{j=1}^{N} \tilde{\theta}_{i j}^{T} \eta\left(x_{j}\right)\right)-\sum_{i=1}^{N}\left[\frac{1}{\gamma_{i 1}} \tilde{\omega}_{i} \dot{\hat{\omega}}_{i}+\frac{1}{\gamma_{i 2}} \sum_{j=1}^{N} \tilde{\theta}_{i j}^{T} \dot{\theta}_{i j}+\frac{1}{\gamma_{i 3}} \tilde{\xi}_{i 0} \dot{\xi}_{i 0}\right] \\
& =\sum_{i=1}^{N}\left[-K_{i} S_{i}^{2}+S_{i} \tilde{\xi}_{i 0}+S_{i} \tilde{\omega}_{i}+S_{i} \sum_{j=1}^{N} \tilde{\theta}_{i j}^{T} \eta\left(x_{j}\right)-\frac{1}{\gamma_{i 3}} \tilde{\xi}_{i 0} \dot{\hat{\xi}}_{i 0}-\frac{1}{\gamma_{i 2}} \sum_{j=1}^{N} \tilde{\theta}_{i j}^{T} \dot{\theta}_{i j}-\frac{1}{\gamma_{i 1}} \tilde{\omega}_{i} \dot{\hat{\omega}}_{i}\right] \\
& =\sum_{i=1}^{N}\left[-K_{i} S_{i}^{2}+\tilde{\xi}_{i 0}\left(S_{i}-\frac{1}{\gamma_{i 3}} \dot{\hat{\xi}}_{i 0}\right)+\sum_{j=1}^{N} \tilde{\theta}_{i j}^{T}\left(S_{i} \eta\left(x_{j}\right)-\frac{1}{\gamma_{i 2}} \dot{\theta}_{i j}\right)+\tilde{\omega}_{i}\left(S_{i}-\frac{1}{\gamma_{i 1}} \dot{\hat{\omega}}_{i}\right)\right] \\
& \leq-\sum_{i=1}^{N} K_{i} S_{i}^{2} \leq 0
\end{aligned}
$$

Then, we know that $\lim _{t \rightarrow \infty} V(t)$ exists, i.e. $V(\infty)$ exists. It is easy to show that $\int_{0}^{\infty} \dot{V}(t) d t$ exists. Hence, we can obtain that

$$
\int_{0}^{\infty} \sum_{i=1}^{N} K_{i} S_{i}^{2} \leq-\int_{0}^{\infty} \dot{V} d t=V(0)-V(\infty)<\infty
$$

Since $\{V(t)\}$ is convergent, from the above analysis we obtain that the solutions $S_{i}, \dot{\hat{\omega}}_{i}, \theta_{i j}$, and $\hat{\xi}_{i j}$ are bound. Because of the boundedness of all the signals, it is obvious from(33) that $\dot{S}_{i}$ is bounded. From (40) and based on the above discussion, this implies that $S_{i} \in L_{2}$. According to Barbalat's Lemma[35], we can get $\lim _{t \rightarrow \infty} S_{i}(t)=0$. Then $e_{i}(t)$ tends to zero at $t \rightarrow \infty$. Thus, we conclude that the asymptotic state tracking can be achieved.

\section{An Example and Simulation Results}

In this example, we consider a large-scale system $T$ composed of two fuzzy subsystems $T_{i}$ defined as

\section{Subsystem 1:}

Rule 1:

If $x_{11}(t)$ is about 0

Then $\left[\begin{array}{l}\dot{x}_{11}(t) \\ \dot{x}_{12}(t)\end{array}\right]=\left[\begin{array}{cc}0 & 1 \\ 1.5 & -2.5\end{array}\right] \times\left[\begin{array}{l}x_{11}(t) \\ x_{12}(t)\end{array}\right]+\left[\begin{array}{l}0 \\ 1\end{array}\right] \times u_{1}\left(t-\tau_{1}\right)+\sum_{j=1}^{2} A_{1 j}^{1} x_{j}\left(t-\tau_{1 j}(t)\right)+f_{1}^{1}\left(x_{i}(t), t\right)$

Rule 2:

If $x_{11}(t)$ is about \pm 2

Then $\left[\begin{array}{l}\dot{x}_{11}(t) \\ \dot{x}_{12}(t)\end{array}\right]=\left[\begin{array}{cc}0 & 1 \\ 1 & -1.5\end{array}\right] \times\left[\begin{array}{l}x_{11}(t) \\ x_{12}(t)\end{array}\right]+\left[\begin{array}{l}0 \\ 1\end{array}\right] \times u_{1}\left(t-\tau_{1}\right)+\sum_{j=1}^{2} A_{1 j}^{2} x_{j}\left(t-\tau_{1 j}(t)\right)+f_{1}^{2}\left(x_{i}(t), t\right)$

Rule 3: 
If $x_{11}(t)$ is about \pm 4

Then $\left[\begin{array}{c}\dot{x}_{11}(t) \\ \dot{x}_{12}(t)\end{array}\right]=\left[\begin{array}{cc}0 & 1 \\ 4 & -3\end{array}\right] \times\left[\begin{array}{c}x_{11}(t) \\ x_{12}(t)\end{array}\right]+\left[\begin{array}{l}0 \\ 1\end{array}\right] \times u_{1}\left(t-\tau_{1}\right)+\sum_{j=1}^{2} A_{1 j}^{3} x_{j}\left(t-\tau_{1 j}(t)\right)+f_{1}^{3}\left(x_{i}(t), t\right)$

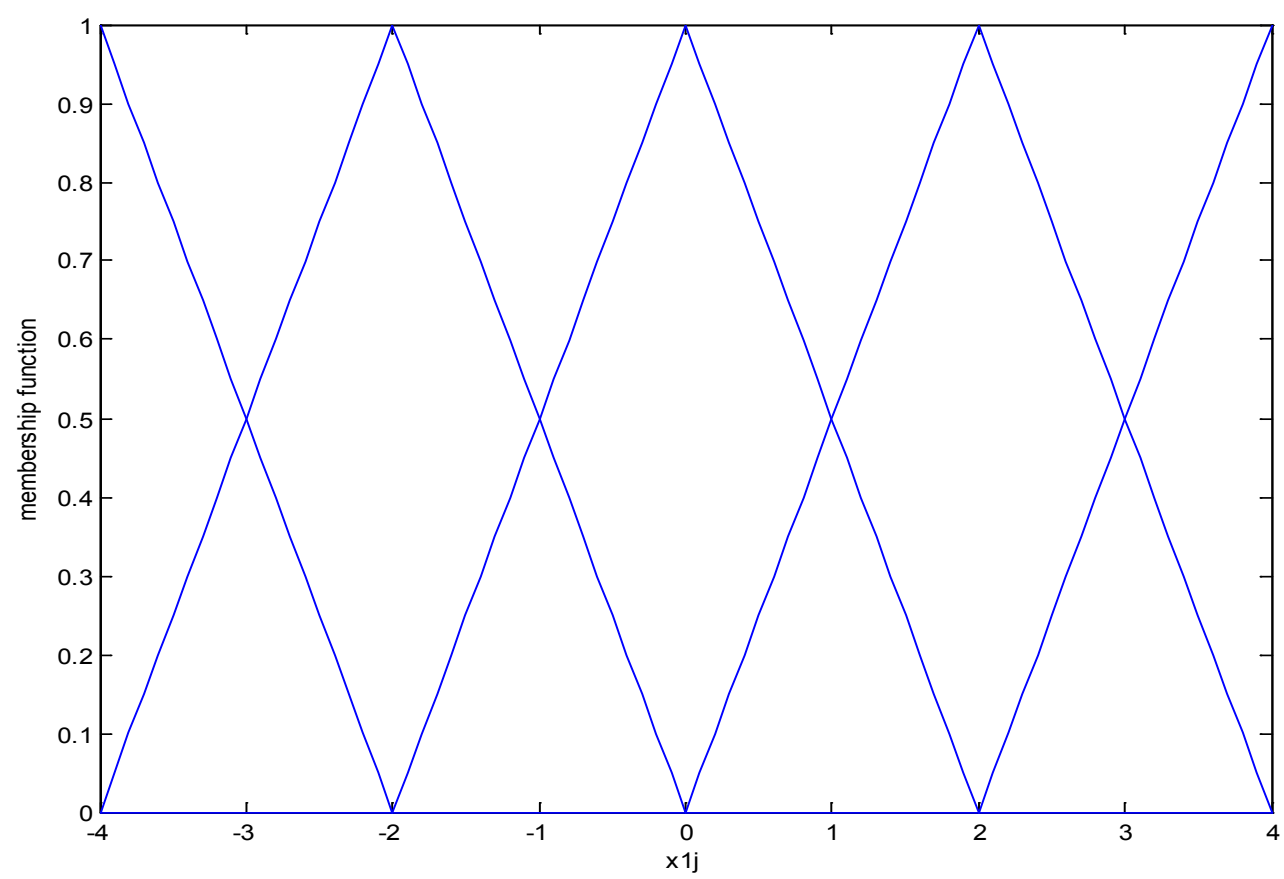

Figure 1. The membership function of $x_{11}$ and $x_{12}$

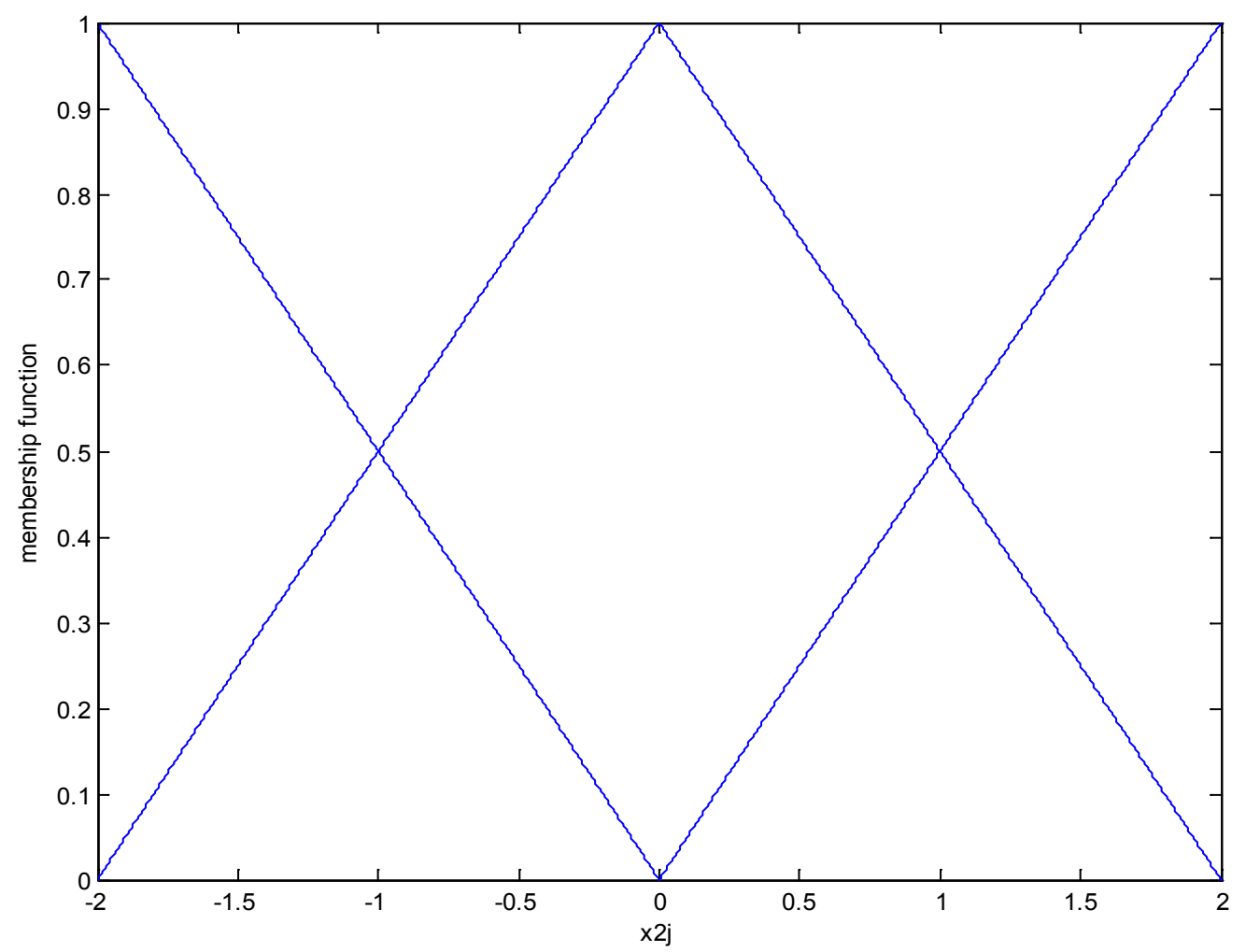

Figure 2. The membership function of $x_{21}$ and $x_{22}$ 


\section{Subsystem 2:}

\section{Rule 1:}

If $x_{21}(t)$ is about 0

Then $\left[\begin{array}{l}\dot{x}_{21}(t) \\ \dot{x}_{22}(t)\end{array}\right]=\left[\begin{array}{cc}0 & 1 \\ 2 & -3.5\end{array}\right] \times\left[\begin{array}{l}x_{21}(t) \\ x_{22}(t)\end{array}\right]+\left[\begin{array}{l}0 \\ 1\end{array}\right] \times u_{2}\left(t-\tau_{2}\right)+\sum_{j=1}^{2} A_{2 j}^{1} x_{j}\left(t-\tau_{2 j}(t)\right)+f_{2}^{1}\left(x_{i}(t), t\right)$

Rule 2:

If $x_{21}(t)$ is about \pm 2

Then $\left[\begin{array}{c}\dot{x}_{21}(t) \\ \dot{x}_{22}(t)\end{array}\right]=\left[\begin{array}{cc}0 & 1 \\ 7.5 & -3.5\end{array}\right] \times\left[\begin{array}{l}x_{21}(t) \\ x_{22}(t)\end{array}\right]+\left[\begin{array}{l}0 \\ 1\end{array}\right] \times u_{2}\left(t-\tau_{2}\right)+\sum_{j=1}^{2} A_{2 j}^{2} x_{j}\left(t-\tau_{2 j}(t)\right)+f_{2}^{2}\left(x_{i}(t), t\right)$

The membership functions for $x_{11}(t), x_{12}(t), x_{21}(t)$, and $x_{22}(t)$ are shown in Figs. 1-2. Moreover, the interconnections and perturbations among two subsystems are given as

$$
\begin{aligned}
& \sum_{j=1}^{2} A_{1 j}^{1} x_{j}\left(t-\tau_{1 j}(t)\right)+f_{1}^{1}\left(x_{i}(t), t\right) \\
& =\left[\begin{array}{c}
0 \\
0.42 \times x_{21}(t-1.5)+0.15 \times x_{22}(t-1.5)+0.25 \times \sin \left(x_{11}(t)\right)+0.25 \times \sin \left(x_{12}(t)\right)+0.5
\end{array}\right] \\
& \sum_{j=1}^{2} A_{1 j}^{2} x_{j}\left(t-\tau_{1 j}(t)\right)+f_{1}^{2}\left(x_{i}(t), t\right) \\
& =\left[\begin{array}{c}
0 \\
0.54 \times x_{21}(t-1.5)+0.1 \times x_{22}(t-1.5)+0.25 \times \sin \left(x_{11}(t)\right)+0.25 \times \sin \left(x_{12}(t)\right)+0.5
\end{array}\right] \\
& \sum_{j=1}^{2} A_{1 j}^{3} x_{j}\left(t-\tau_{1 j}(t)\right)+f_{1}^{3}\left(x_{i}(t), t\right) \\
& =\left[\begin{array}{c}
0 \\
0.38 \times x_{21}(t-1.5)+0.15 \times x_{22}(t-1.5)+0.25 \times \sin \left(x_{11}(t)\right)+0.25 \times \sin \left(x_{12}(t)\right)+0.5
\end{array}\right] \\
& \sum_{j=1}^{2} A_{2 j}^{1} x_{j}\left(t-\tau_{2 j}(t)\right)+f_{2}^{1}\left(x_{i}(t), t\right) \\
& =\left[\begin{array}{c}
0 \\
0.25 \times x_{11}(t-2)+0.15 \times x_{12}(t-2)+0.23 \times \sin \left(x_{21}(t)\right)+0.23 \times \sin \left(x_{22}(t)\right)+0.3
\end{array}\right] \\
& \sum_{j=1}^{2} A_{2 j}^{2} x_{j}\left(t-\tau_{2 j}(t)\right)+f_{2}^{2}\left(x_{i}(t), t\right) \\
& =\left[\begin{array}{c}
0 \\
0.23 \times x_{11}(t-2)+0.17 \times x_{12}(t-2)+0.23 \times \sin \left(x_{21}(t)\right)+0.23 \times \sin \left(x_{22}(t)\right)+0.3
\end{array}\right]
\end{aligned}
$$




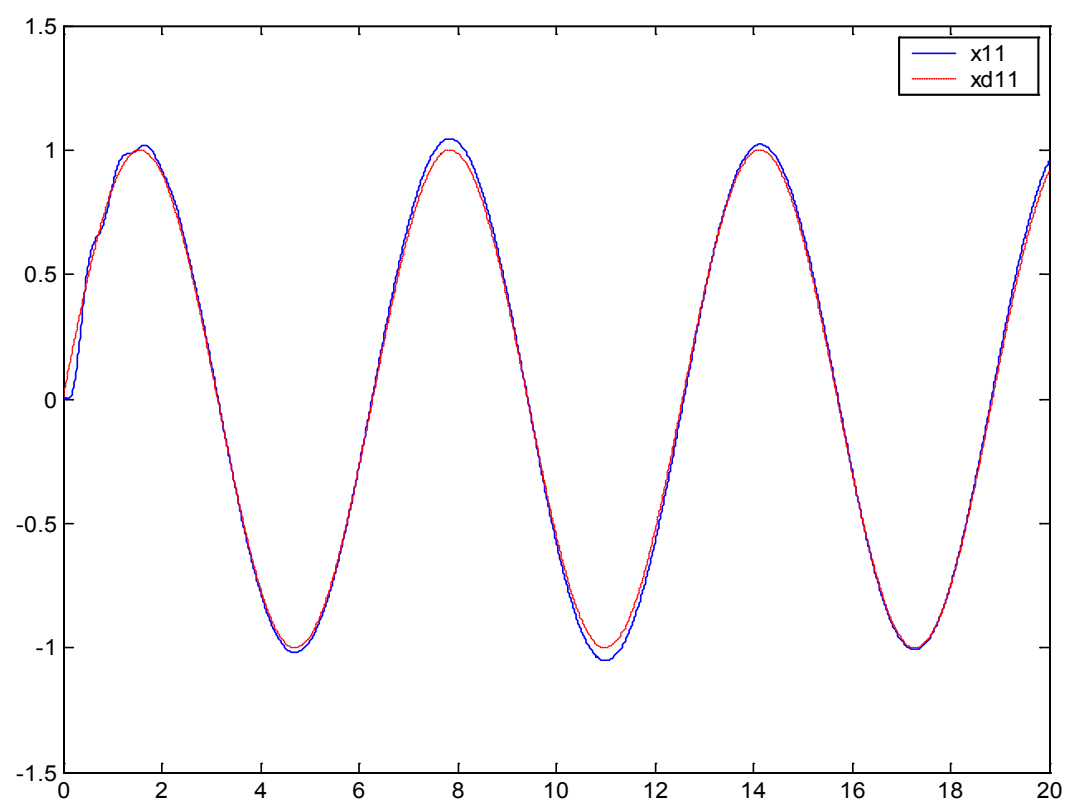

Figure 3. Trajectory of the state $x_{11}(t)$ and desired state $x_{d 11}(t)$

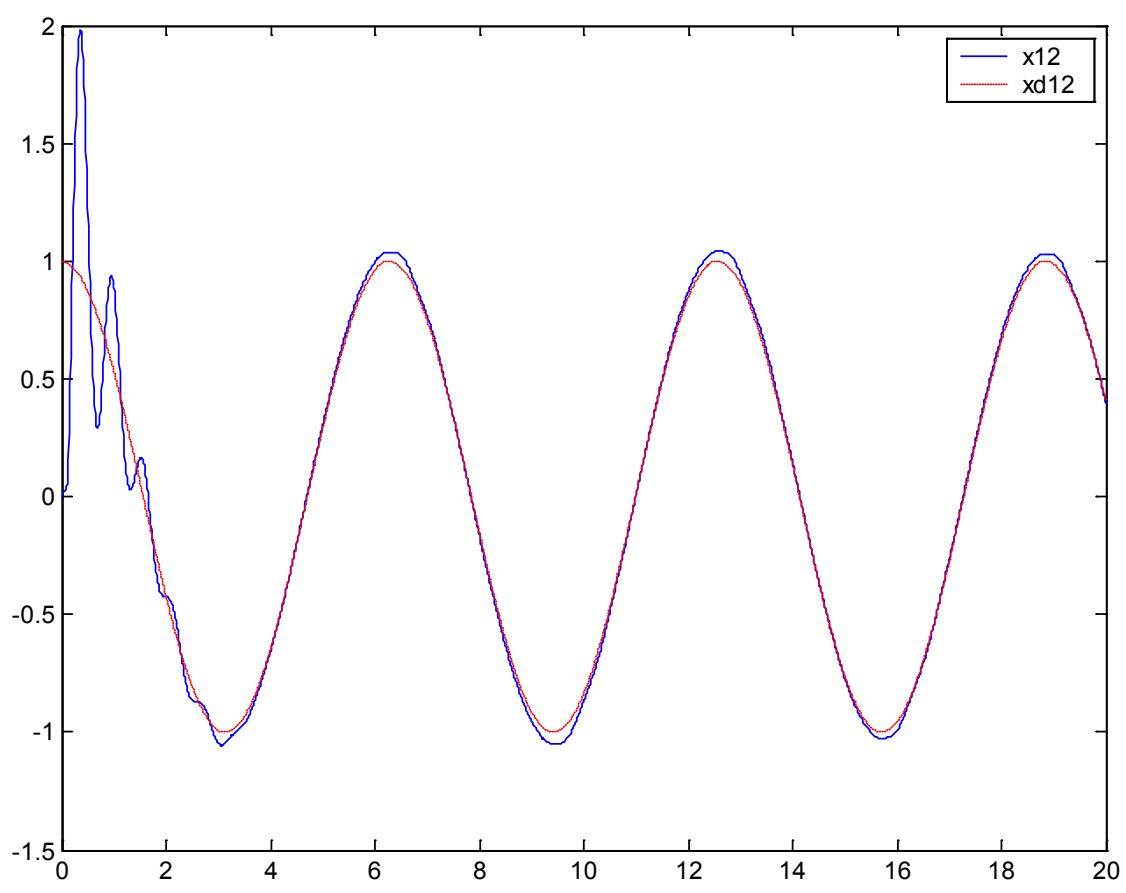

Figure 4. Trajectory of the state $x_{12}(t)$ and desired state $x_{d 12}(t)$

The desired state are selected as $x_{d 11}(t)=\sin (t), x_{d 12}(t)=\cos (t), x_{d 21}(t)=\sin (t)$, and $x_{d 22}(t)=\cos (t)$. The control objective is to design a controller $u_{i}$ such that the state trajectory $x_{i}(t)$ of each subsystem can track the desired state $x_{d i}(t)$.

In accordance with (22), the decentralized switching manifolds for the subsystems are chosen as follows:

$S_{1}=e_{12}(t)+c_{11} e_{11}(t)$,

$S_{2}=e_{22}(t)+c_{21} e_{21}(t)$, 
where $c_{11}=c_{21}=4$. The initial values are chosen as $\hat{\omega}_{1}(0)=\hat{\omega}_{2}(0)=0, \quad x_{11}(0)=x_{12}(0)=0$, $x_{21}(0)=x_{22}(0)=0, \theta_{21}(0)=\theta_{22}(0)=\mathbf{1}, \theta_{11}(0)=\theta_{12}(0)=\mathbf{1}$, and $\xi_{10}(0)=\xi_{20}(0)=0$, and $\alpha_{11}=\alpha_{21}=50$, $\alpha_{12}=\alpha_{22}=15, \quad \beta_{1}=\beta_{2}=3$, and $\gamma_{11}=\gamma_{12}=\gamma_{13}=\gamma_{21}=\gamma_{22}=\gamma_{23}=1, \quad$ and $K_{1}=7, \quad K_{2}=7$, and $\tau_{1}=0.12 \mathrm{sec}$ and $\tau_{2}=0.14 \mathrm{sec}$. Simulation results are shown in Figs. 3-8. Figs. 3-6 show the trajectories of the states $x_{1}(t), x_{2}(t)$ and desired states $x_{d 1}(t), x_{d 2}(t)$. Fig. 7 and Fig. 8 show the responses of the control laws $u_{1}(t)$ and $u_{2}(t)$, respectively.

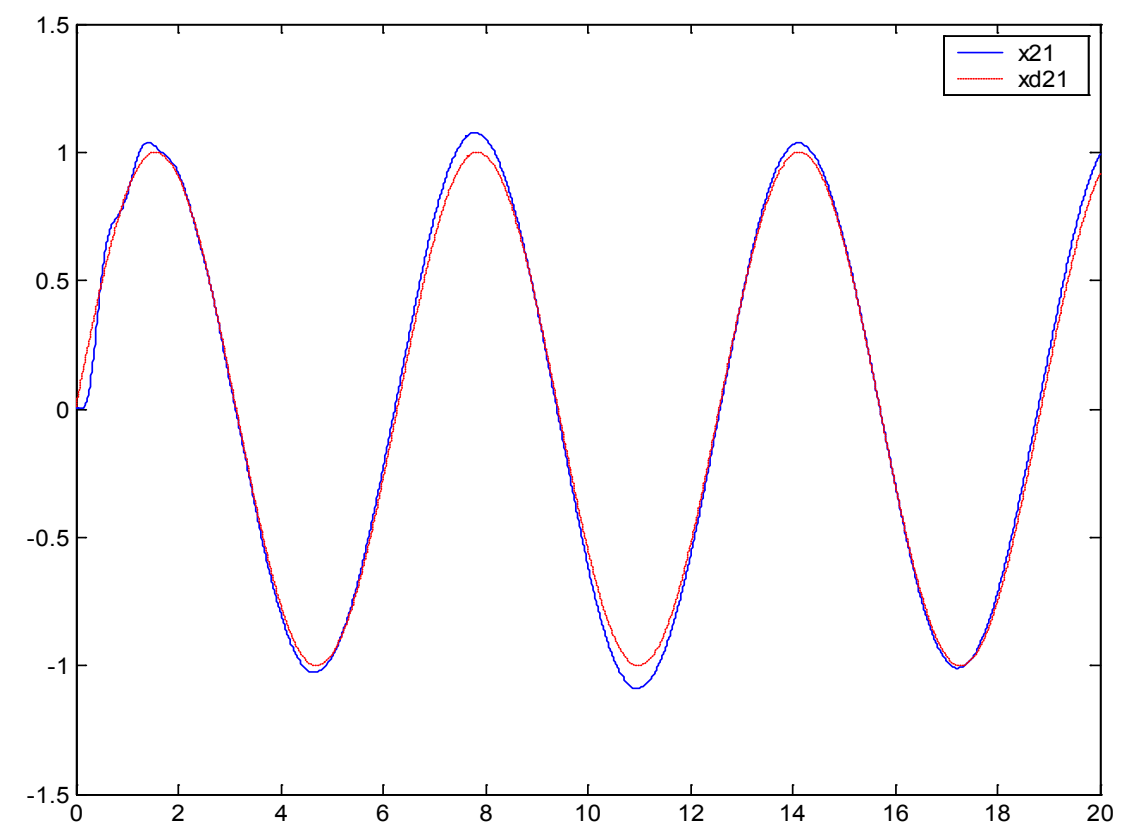

Figure 5. Trajectory of the state $x_{21}(t)$ and desired state $x_{d 21}(t)$

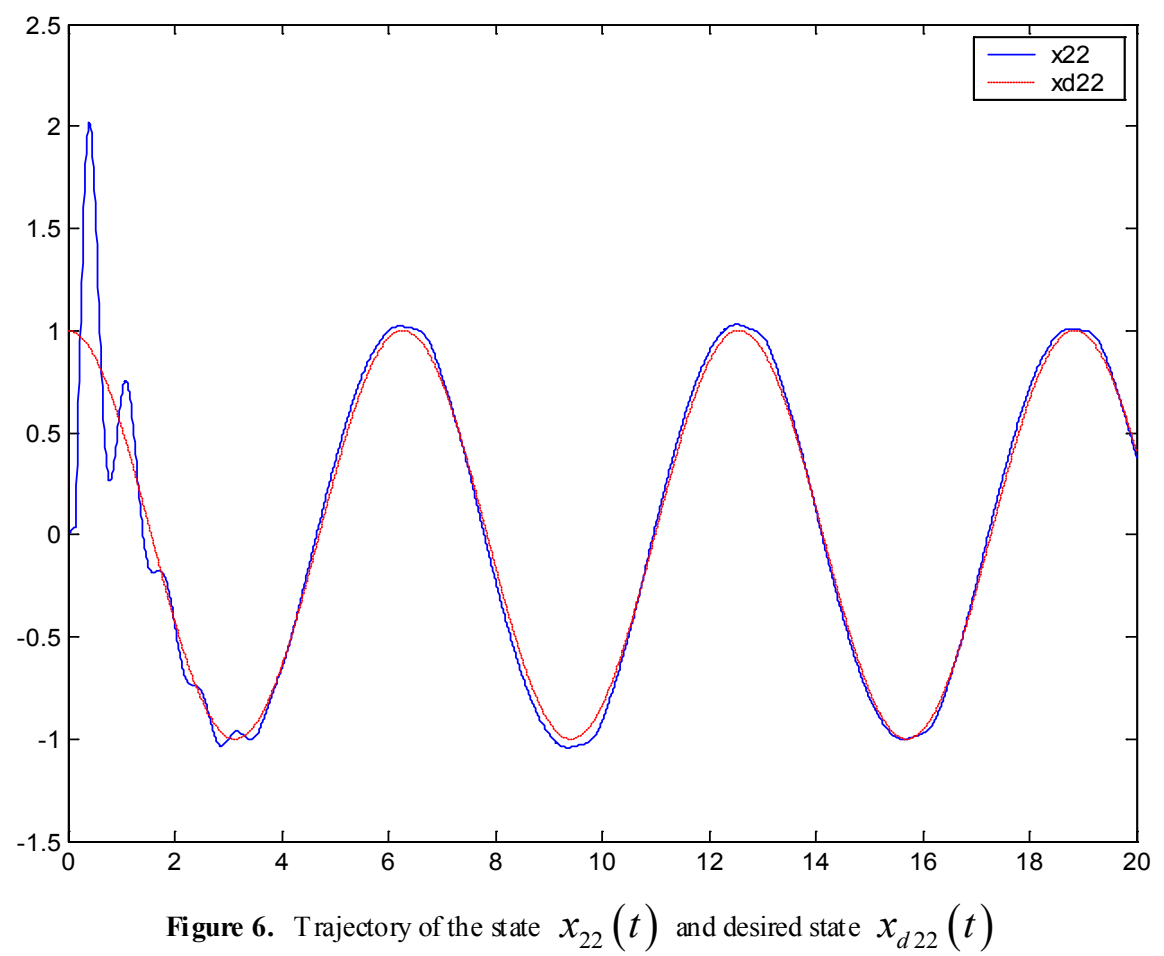




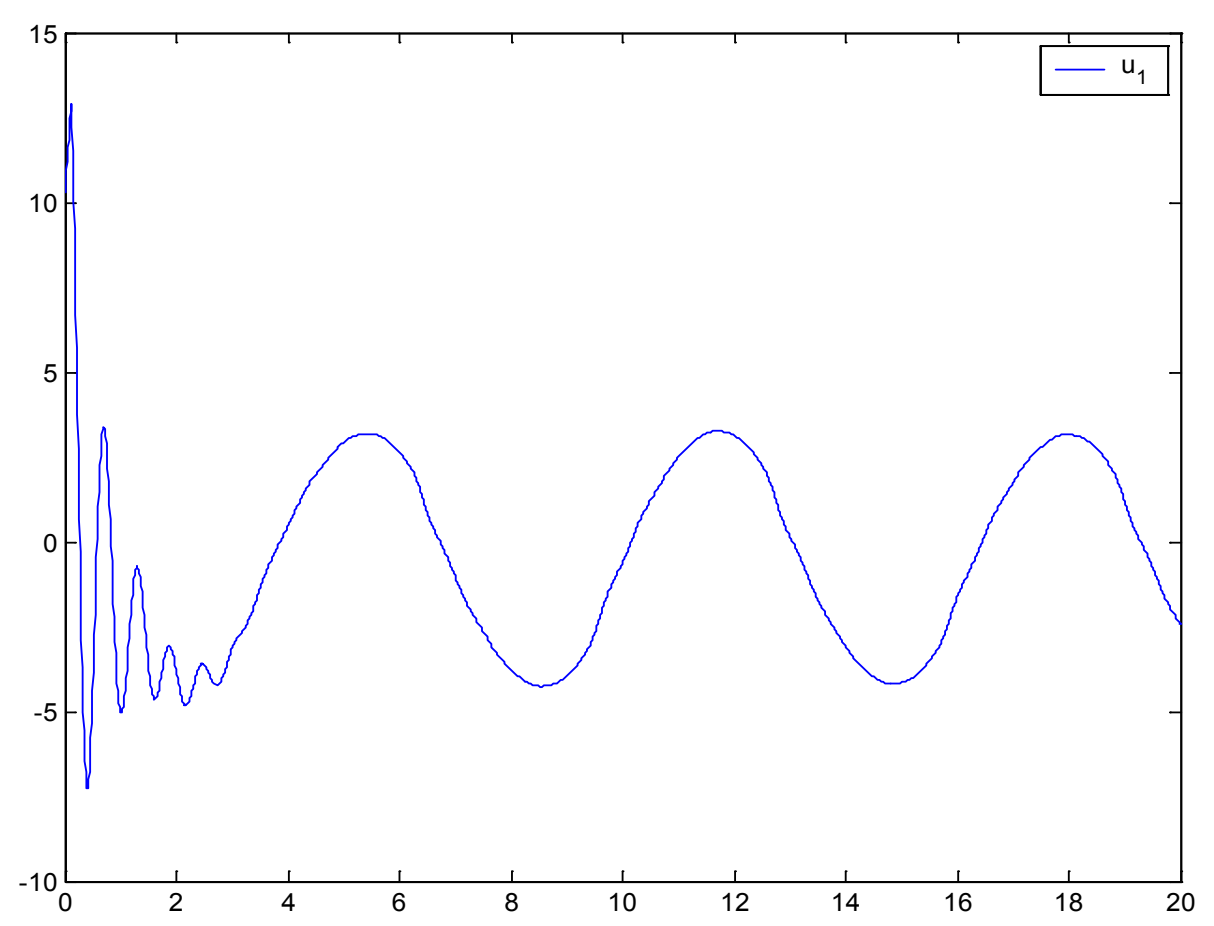

Figure 7. The control signal $u_{1}(t)$

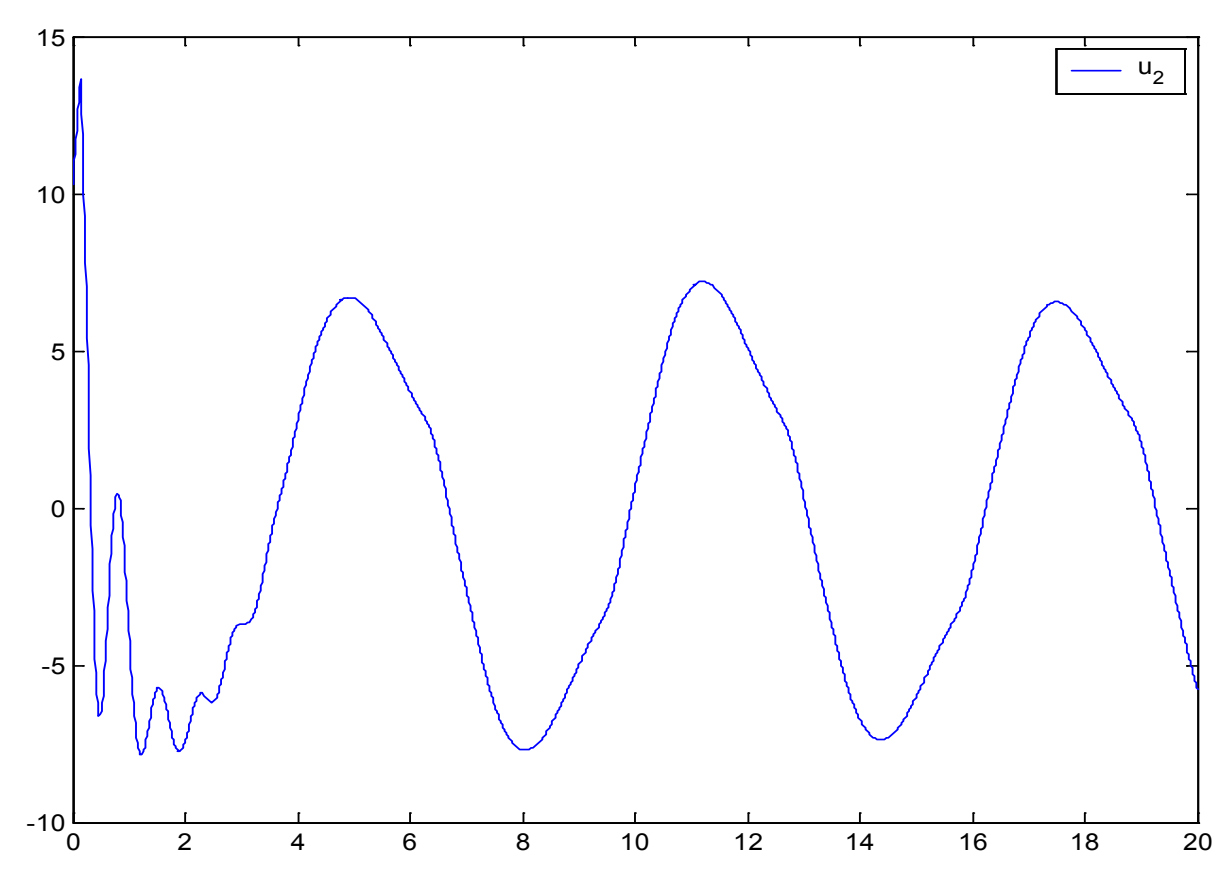

Figure 8. The control signal $u_{2}(t)$

\section{Conclusions}

The problem of robust stability and output tracking control for a class of uncertain large-scale input-delay systems with time-delay interconnections is investigated in this paper. In addition, a feasible and systematic design method is provided to develop the decentralized fuzzy model-based adaptive sliding mode controller with some adaptive laws to approximate the upper bounds of the uncertainties including the time-delay interconnections and the delayed input. Based on the Lyapunov stability theorem, the proposed control scheme not only guarantees the robust stability of the whole closed-loop system, but also achieves the good tracking performance. An example and simulation results are illustrated to verify the effectiveness of the proposed controller in this paper. 


\section{REFERENCES}

[1] H. S. Wu, "Decentralized adaptive robust control for a class of large-scale systems including delay ed state perturbations in the interconnections," IEEE Trans. Automat. Contr. Vol. 47, No. 10, pp. 1745-1751, 2000.

[2] T. P. Zhang and C. B. Feng, "Decetralized adaptive fuzzy control for large-scale nonlinear systems," Fuzzy Sets and Systems, vol. 92,pp. 61-70, 1997.

[3] J. Zhou and C.Y.Wen, "Decentralized backstepping adaptive output tracking of interconnected nonlinear systems," IEEE Trans. Autom. Control, vol. 53, no. 10, pp. 2378-2384, Nov. 2008.

[4] S. C. Tong, C. L. Liu, and Y. M. Li, "Fuzzy-adaptive decentralized output-feedback control for large-scale nonlinear systems with dynamical uncertainties," IEEE Trans. Fuzzy Syst., vol. 18, no. 5, pp. 845-861, Oct. 2010.

[5] K. K. Shy u, W. J. Liu, and K. C. Hsu, "Decentralized variable structure control of uncertain large-scale systems containing a dead-zone," IEE Proc.-Control Theory Appl., vol. 150, pp. 467-475, 2003.

[6] S. C. Tong, C. L. Liu, Y. M. Li, and H. G. Zhang, “Adaptive fuzzy decentralized control for large-scale nonlinear systems with time-varying delays and unknown high-frequency gain sign," IEEE Trans. Syst.,Man, Cybern. B, Cybern., vol. 41, no. 2, pp. 474-485, Apr. 2011.

[7] J. T. Tsay, P. L. Liu, and T. J. Su, "Robust stability for perturbed large-scale time-delay systems," IEE Proc.-Control Theory Appl., vol. 143, pp. 233-236, 1996.

[8] Z. H. Guan, G. Chen, X. Yu, and Y. Qin, "Robust decentralized stabilization for a class of large-scale time-delay uncertain impulsive dynamical systems," Automatica, vol. 38, pp. 2075-2084, 2002.

[9] X. Z Liu, M. D. Georgi, Y. W. Jing, and S. Y. Zhang, "Robust decentralized stabilization for large-scale systems with multiple time-varying delays and nonlinear uncertainties," Proc. of 2003 IEEE conference, vol. 1, pp. 1323-1326, 2003.

[10] H. B. Zhang, X. F. Liao, X. D. Li, and J. B. Yu, "LMI-based approach for stability analysis of fuzzy large-scale system with time delays," Proc. IEEE conf. Circuits and Sy stems, vol. 2, pp. 1401-1405, 2004.

[11] H. P. Pang and L. P. Wang, "Global robust sliding mode control for a class of uncertain time-delay systems," Proceedings of the Ninth International Conference on Machine Learning and Cybernetics, Qingdao, pp.910-915, July 2010.

[12] C. S. Chiu and T. S. Chiang, "Robust output regulation of T-S fuzzy systems with multiple time-varying state and input delay s," IEEE Trans. Fuzzy Syst., vol. 17, no. 4, pp. 962-975, Aug. 2009.

[13] D. Yue and J. Lam, "Stabilising controller design for uncertain systems with time-varying input delay," IEE Proc.-Control Theory Appl, vol. 151, pp. 699-705, 2004.

[14] S. C. Qu and Y. J. Wang, "Sliding mode control for a class of uncertain input-delay systems," Proc. Of the 5th World Congress on Intelligent Control and Automation, vol. 2, pp. 1184-1186, 2004.
[15] L. X. Wang, "Stable adaptive fuzzy control of nonlinear systems," IEEE Trans. Fuzzy Syst., vol. 2,pp. 146-155, 1993.

[16] B. Chen, X. Liu, and S. Tong, "New delay-dependent stabilization conditions of T-S fuzzy systemswith constant delay," Fuzzy Sets Syst., vol. 158, no. 20, pp. 2209-2224, 2007.

[17] H. Gao, Y. Zhao, and T. Chen, " $H \infty$ Fuzzy control of nonlinear systems under unreliable communication links," IEEE Trans. Fuzzy Syst., vol. 17, no. 2, pp. 265-278, Apr. 2009.

[18] V. D. Daniel and T. Yu, "Adaptive robust fuzzy control of nonlinear systems," IEEE Trans. Syst., Man, Cybern. B, vol. 34, No. 3, pp. 1596-1601, 2004.

[19] C. C. Hua and S. X. Ding, "Decentralized networked control system design using T-S fuzzy approach," IEEE Trans. Fuzzy Syst., vol. 20, no. 1, pp. 9-21, Feb. 2012.

[20] Y. Y. Cao and P. M. Frank, "Stability analysis and synthesis of nonlinear time-dealy systems via linear Takagi-Sugeno fuzzy models," Fuzzy Sets and Systems, vol. 124, pp. 213-229, 2001.

[21] C. S. Tseng, B. S. Chen, and H. J, Uang, "Fuzzy tracking control design for nonlinear dynamic systems via T-S fuzzy model," IEEE Trans. Fuzzy Syst., vol. 9, No. 3, pp. 381-392, 2001.

[22] X. P. Guan and C. L. Chen, "Delay-depedent guaranteed cost control for T-S fuzzy systems with time delays," IEEE Trans. Fuzzy Syst., vol. 12, No. 2,pp. 236-249, 2004.

[23] H. Katay ama and A. Ichikawa, "Hळ control for sampled-data nonlinear systems described by Takagi-Sugeno fuzzy systems," Fuzzy Sets and Systems, vol. 148, pp. 431-452, 2004.

[24] Y. Xia, G.P. Liu, P. Shi, J. Chen, D. Rees and J. Liang, "Sliding mode control of uncertain linear discrete time systems with input delay," IET Control Theory \& Applications, vol. 1, no. 4, pp. 1169-1175, 2007.

[25] W. Chang, J. B. Park, Y. H. Joo, and G. Chen, "Design of robust fuzzy-model-baesd controller with sliding mode control for SISO nonlinear systems," Fuzzy Sets and Systems, vol. 125, pp. 1-22, 2002.

[26] C. C. Chiang, K. M. Shen, and M. Y. Tsai, "Robust fuzzy-model-based sliding mode controller for uncertain nonlinear input-delay systems," IEEE International Conf. on Syst., Man and Cyber., vol. 3, pp. 2243-2248, 2004.

[27] C. L. Hwang, "A novel Takagi-Sugeno-based robust adaptive fuzzy sliding-mode controller,” IEEE Trans. Fuzzy Syst., vol. 12, No. 5, pp. 676-687, 2004.

[28] C. C. Hsiao, S. F. Su, and C. C. Chuang, "A sliding manner compensation control for affine TSK fuzzy control systems," Proc. Of the third International Conf. on Machine Learning and Cyber., vol. 7, pp. 4374-4379, 2004.

[29] J. H. Zhang, P. Shi, and Y. Q. Xia, "Robust adaptive sliding-mode control for fuzzy systems with mismatched uncertainties," IEEE Trans. Fuzzy Syst., vol. 18, no. 4, pp. 700-711, Aug. 2010.

[30] Y. S. Huang, D. Q. Zhou, and X. X. Chen, "Decentralized direct adaptive output feedback fuzzy $H \propto$ tracking design of 
large-scale nonafine nonlinear systems," Nonlinear Dyn., vol. 58, no. 1-2, pp. 153-167, 2009.

[31] S. L. Xie and L. H. Xie, "Stabilization of a class of uncertain large-scale stochastic systems with time delays," Automatica, vol. 36, pp. 161-167, 2000.

[32] B. Labibi, B. Lohmann, A. K. Swdigh, and P. J. Maralani, "Decentralized stabilization of large-scale systems via state-feedback and using descriptor systems," IEEE Trans. Syst., Man, Cybern. A, vol. 33, No. 6, pp. 771-776, 2003.

[33] W. J. Wang and L. Luoh, "Stability and stabilization of fuzzy large-scale systems," IEEE Trans. Fuzzy Syst., vol. 12, No. 3, pp. 309-315, 2004.

[34] F. H. Hsiao, J. D. Hwang, C. W. Chen, and Z. R. Tsai, "Robust stabilization of nonlinear multiple time-delay large-scale systems via decentralized fuzzy control," IEEE Trans. Fuzzy Syst., vol. 13, No. 1, pp. 152-163, 2005.

[35] J. J. Slotine and W. Li, Applied Nonlinear Control. Englewood Cliffs. N J: Prentice Hall, 1997.

[36] J. T. Spooner, and K. M. Passion, "Decentralized adaptive control of nonlinear system using radial basis neural networks," IEEE Trans. Automat. Contr., vol. 44, pp. 2050-2057, Nov. 1999.

[37] S. Tong, H. X. Li, and G. Chen, "Adaptive fuzzy decentralized control for a class of large-scale nonlinear systems," IEEE Trans. Syst., Man. Cybern. B, vol. 34, pp. 770-775, Feb. 2004. 